\title{
Understanding the Benefits and Success Factors of Enterprise Architecture
}

\author{
Muhammad Baharudin Jusuf \\ Universitas Indonesia \\ muhammad.baharudin.jusuf@gmail.com
}

\author{
Sherah Kurnia \\ The University of Melbourne \\ sherahk@unimelb.edu.au
}

\begin{abstract}
Enterprise Architecture (EA) is considered as a solution to reduce IT implementation failure, improve profitability and enhance business-IT alignment within organizations. However, explanations and evidence of EA benefits and success factors in the existing literature are still limited. Therefore, this study aims to explore how EA creates value to organizations through a qualitative study employing interviews with EA experts. This study contributes to the current knowledge of EA by providing a validated list of EA benefits and success factors. The study identified 40 EA benefits that are grouped into five categories (operational, managerial, strategic, IT infrastructure and organizational) and thirty-seven EA success factors categorized into product quality, infrastructure quality, service delivery quality and organizational anchoring. This study offers a number of implications for research and practice.
\end{abstract}

\section{Introduction}

The definition of EA has evolved over the last few years. Several studies describe EA as an abstraction of organizations' current states, future states and how to transition towards the intended future states [1, 2]. Others [3, 4] interpret EA as a blueprint of organizations. There is no exact definition of EA. This study defines EA as a portrayal of a high-level view of current and future states of organization's data, processes, IT systems, their relationships, as well as a roadmap for achieving the intended future from the current state $[5,6]$.

There are currently only a few existing studies which specifically focus on EA benefits (e.g., [7], [8]). Although those studies have identified a number of EA benefits such as supported IT implementation [9], increased effectiveness and efficiency of IT benefits delivery [10] and improved business-IT alignment in organizations [7], they are only based on anecdotal evidence. Further studies involving empirical data are still required to help organizations understand the actual benefits so they can better manage their expectations towards EA [11]. Furthermore, factors that impact the likelihood of achieving EA benefits by organizations are still not well explored since the explanation of how EA produces value is currently limited [6]. Since EA has become an important focus in many organizations [9], exploring EA benefits and success factors is beneficial for the development of organizations.

After reviewing selected existing studies critically, several gaps have been identified. Generally, most of the existing studies focusing on EA benefits and success factors are based on literature review only. Furthermore, most benefits and success factors are explained and discussed in a fragmented manner across those existing studies (e.g., [12], [13], [9], [14]). Moreover, only two studies [5, 15] identified involve Australia as the study context. Therefore, further efforts to synthesize the various benefits and success factors as well as empirical validations, explorations and explanations of what value organizations can gain from EA and what factors drive the achievement of the benefits within a specific context are still required.

Therefore, this study aims to enhance the current understanding of what value and how EA brings value to organizations through a combination of literature synthesis and qualitative interviews with EA experts in Australia. Specifically, there are two questions addressed in this study:

- What are the benefits of EA for organizations?

- What are the drivers of the EA benefits?

This study provides a preliminary assessment of the benefits and success factors identified from the literature. The overall findings of the study include forty validated EA benefits and thirty-seven validated EA success factors. Furthermore, the study identifies a number of benefits and benefit drivers that have not been previously identified. Moreover, many benefits and success factors have been further clarified in this study. Finally, as a summary of this study's findings, a preliminary model called EA Success Factors and 
Benefit Model (EA-SFBM) is proposed to help researchers and practitioners be aware of the different types of EA benefits and benefit drivers, which can guide future studies, the management of expectations towards EA benefits and the strategy formulation to increase the chance of realizing EA benefits.

The paper is structured as follows. In the next section, the research methodology is briefly explained. Then, syntheses of EA benefits and benefit drivers identified from the literature are presented. The findings from the interviews with EA experts are then compared with the findings of the first phase. Finally, this paper is concluded, and the contributions and limitations are outlined.

\section{Research Methodology}

This study involves two phases: critical literature analysis and synthesis and qualitative interviews with EA experts to validate the list of benefits and benefit drivers identified from the first phase. The first phase was conducted from the beginning of the study in July 2015 until early of 2016. It employs exploratory search approach using tools such as Google Scholar and University of Melbourne search engine which are connected to numerous online databases. This approach is suitable to get a good coverage of relevant publications [5]. Several search terms used include "IT architecture", "IS architecture", "EA architecture", "EA benefits", "EA advantages", "EA success factors", and "EA benefit drivers". More than thirty papers about EA benefits and success factors were identified. After further screening, fifteen highly relevant papers were selected to be included in this study.

The second phase involves qualitative interviews with EA experts from Australian organizations. This approach is considered appropriate because it enables a deep exploration of the meaning of a phenomenon being studied and the relevant experience of the study participants [16]. Moreover, the qualitative approach also produces a comprehensive, holistic, expansive, and rich description of the context, participants, and activities of a phenomenon [17]. The merits of qualitative approach are consistent with the research questions of this study which explore benefits of EA that organizations can expect and factors that drive the achievement of EA benefits. This second phase serves as a preliminary assessment of the identified benefits and success factors, and corroborates the findings in the first phase to better understand the EA benefits and success factors.

Each interview was conducted face-to-face. Follow-up conversations over the phone or email were sometimes conducted for further clarification. The interviews were semi-structured, and most of the questions were open-ended. In this paper, only five interviews were included: three interviewees are from the retail industry, one from the finance industry, and one from the service industry as summarized in Table 1. The organizations involved are considered as leading organizations in EA practice in Australia. All of the experts have more than twenty-five years of experiences. Each participating organization has more than four EA teams.

Table 1. Research Participants

\begin{tabular}{|c|c|c|c|c|}
\hline ID & Industry & $\begin{array}{l}\text { Org. } \\
\text { Size }\end{array}$ & $\begin{array}{c}\text { EA } \\
\text { Team }\end{array}$ & $\begin{array}{c}\text { Expr. } \\
\text { (years) }\end{array}$ \\
\hline Retail1 & Retail & $>25000$ & 4 & 35 \\
\hline Retail2 & Retail & $>198000$ & 9 & 25 \\
\hline Retail3 & Retail & $>100000$ & 4 & 25 \\
\hline Finance1 & Finance & $>300$ & 6 & 30 \\
\hline Utility1 & Utility & $>2500$ & 5 & 25 \\
\hline
\end{tabular}

This study employs three steps of qualitative data analysis [21]: open coding, axial coding, and selective coding. In the first step, each relevant theme was identified, described and highlighted [23]. All identified concepts related to benefits and benefit drivers were coded and recorded. Then, the recorded concepts were sorted and grouped. Lastly, in the selective coding, some core themes which cover all the ideas from all datasets are chosen. In the end, each of the EA benefits and success factors identified from the data analysis was then compared with the results from the literature synthesis.

\section{Synthesis of EA Benefits}

Based on the literature synthesis, thirty-seven EA benefits have been identified as shown in Table 2 . Using Shang and Seddon [18] benefit framework for Enterprise Systems, the identified benefits include three operational benefits, eight managerial benefit, twelve strategic benefits, nine IT infrastructure benefits and five organizational benefits.

First, EA impacts operational aspects or day-today operations in organizations. Shang and Seddon [18] define operational activities as activities that acquire and consume organization's resources. EA improves business operations and processes which increase organizations' performance [12]. EA helps organizations improve IT solution efficiency and effectiveness [19] and shorten delivery times [9].

Second, EA benefits managerial activities which are related to allocating or controlling resources, monitoring operations and supporting decisions [11]. 
EA provides a better asset and resource management to gain optimal results [20]. EA helps organizations comply with external regulations, standards and quality requirements [7]. EA improves IT management and its related costs [21]. EA increases organizations' change capability, reduces risk and improves business continuity [7]. EA supports staff management by increasing staff knowledge and skills [13]. EA manages the IT complexity and business operations [20], helps project scoping [10], and supports portfolio management [7].

Third, most EA benefits fall into the strategic benefit category. Shang and Seddon [18] define strategic activities as actions that are related to organization's efforts in maintaining and creating competitive advantage. EA improves the alignment between stakeholders and organizations' strategies [13] and between business and IT [15]. EA helps organizations in dealing with their customers' needs [22], improves innovation and opens new opportunities [11]. EA also increases stakeholders' satisfaction and supports organizations in managing their long-term investments [13]. Besides, EA improves the probability of project success [19], quality of solutions [12], and profitability / return on investment [19]. Moreover, EA provides a roadmap to guide strategic decision-making [20].

Fourth, EA impacts positively on organizations' IT infrastructure which is described by Shang and Seddon [18] as IT resources which are employed as the foundation for current and future use of IT. EA supports organizations' agility, flexibility, and responsiveness towards future change [21]. EA helps organizations to utilize and realize IT benefits [11, 22]. Furthermore, EA increases the interoperability and integration between IT infrastructures [20] and improves its reusability [7], stability and security [13]. It also enhances the standardization of IT infrastructures [14], reduces redundancy [21] which leads to reduced IT costs [5]. Besides, EA supports the deployment of IT resources and helps the organization initialize projects [7, 20].

Last, EA affects organizational aspects in terms of communication, organizational learning, common vision development, etc. [11]. EA facilitates the creation and maintenance of organization's common visions [11] and enables stakeholders to have a better communication by providing a high quality of information [9]. EA supports collaboration among the stakeholders [7], improves information sharing [9], and provides a holistic view of organizations [15].

\section{Synthesis of EA Success Factors}

Based on the existing literature, thirty EA success factors were identified as shown in Table 3. Those success factors are grouped into four categories based on [19]: seven product quality factors, twelve infrastructure quality factors, five service delivery quality factors and six organizational anchoring factors.

First, EA success is affected by the quality of EA products. Lange et al. [14] define EA products as the output where information related to EA is stored. Organizations have a complete and detailed view of as-is architecture [11] and the required future conditions [21]. A good and clear roadmap which considers dependencies between distinct transformation's steps is necessary $[8,21]$. EA should also maintain and structure its principles to describe and evaluate EA itself $[9,11]$. Iterative refinement is required to response the changing condition and to reduce risk [14]. EA has to use organization's focus as its orientation [19]. The products also have to be understandable by various stakeholders [8].

Second, organizations should consider the quality of infrastructure. Lange et al. [14] define EA infrastructure quality as the quality of formal conditions and foundation where EA function runs. The availability of EA framework [21], tool support [11], and reference architecture which describes how each architectural items related one to another [7] are essential to make EA functions run well. EA should be supported with sufficient skills [11] and resources [5]. A clear mandate has to be defined and maintained to address organization's expectation towards EA [11] including the reasons and goals of implementing EA [12]. Besides, organizations have to define the degree of centralizations [11], including the governance mechanism [14] and accountability of each activity [22]. EA principles which are contained in the EA products should be established [21]. Also, organizations should have an excellent change management capability [12].

Third, EA success is also affected by the quality of EA service delivery. Lange et al. [14] describe this category as the quality of the actual services provided to stakeholders. In delivering EA services, good communication to all stakeholders has to be established [11]. There should be sufficient top management support [10, 19]. Furthermore, EA should be implemented gradually [12] with a proper performance measurement [8].

Finally, organizations should also give attention to the conditions that help embed and ground EA to organizations [14]. Top management commitment towards EA is essential [14]. All stakeholders should consider EA in each of their decisions [11]. Therefore, they should have an adequate 
understanding of EA [21]. Furthermore, EA should fit the organizations' culture since it determines how people deal with EA [14]. Finally, the involvement of EA team is required [19] to facilitate collaboration between stakeholders $[5,20]$.

\section{Overall Findings and Discussion}

This section presents the overall findings related to EA benefits and success factors based on the literature analysis and the preliminary validation with five EA experts. The benefit framework of Shang and Seddon [18] and success factors categorization of Lange et al. [14] are employed. A model called EA Success Factor and Benefit Model (EA-SFBM) is also proposed in this section to summarize the findings and the answers to the research questions.

\subsection{EA Benefits}

Almost all of the EA benefits identified in the existing literature were highly supported by EA experts. As in Table 2, forty EA benefits have been identified: three benefits identified from the literature were adjusted for clarity, one was split into two distinct benefits, and two are new factors. New benefits are indicated in italics. Those benefits cover three operational benefits, nine managerial benefits, thirteen strategic benefits, nine IT infrastructure benefits, and six organizational benefits. The listed benefits in each category are ordered from those most acknowledged to those least acknowledged by EA experts. Increased efficiency and effectiveness, reduced complexity, improved quality, integration and interoperability, and enhanced creation and maintenance of common vision are the highest ranked EA benefits confirmed by experts in this study.

\section{Operational benefits}

The interviews with EA experts provide evidence of the relevance of all operational benefits identified in the literature. For example, Foorthuis [19] argue that EA results in a higher level of efficiency, effectiveness, and control (B2). This claim is acknowledged by all experts. For example, an EA expert asserts: "If I've got 2 people that do Java, and 2 people that do.NET, and 2 people that do Python, and 2 people that do whatever, that's a lot less efficient than having 6 people that do .Net and they're able to support everything because then you get economies of scale." (Retail3)

Also, the interviews confirm that EA has the ability to reduce redundant efforts, processes, and operations which increase organizations' performance (B1). Besides, evidence is obtained to support the claimed benefit that EA reduces the required time in delivering solutions (B3).

\section{Managerial benefits}

All of the identified managerial benefits from the literature were supported by the EA experts. Boh and Yellin [20] acknowledge EA's ability to manage and reduce the complexity of IT and business operations (B10). This benefit is confirmed by all EA experts. An expert describes: "So, I think without enterprise architecture, different approaches in different ways, and we would end up with a store of technologies that we would have to maintain, instead of a relatively small subset of technologies." (Retail3)

Second, all EA experts also acknowledge that EA improves the risk and change management (B8). An EA expert asserts that risk assessment has become one of Enterprise Architects' tasks: "Risk assessments absolutely - we do have a risk and compliance area more or less an umbrella so I'm given a portion of the risk to assess." (Finance1) This is in line with Boucharas et al. [7] who argue that EA helps organizations reduce risk and improve business continuity.

Third, all experts also indicate the ability of EA in managing portfolio, mapping and optimizing capabilities (B11). The current literature only focuses on portfolio management. For example, Tamm [5] argues that EA increases the quality of organizations' portfolio and support the evaluation of the portfolio. However, our study shows that EA also supports mapping capabilities and optimization, which are related to portfolio management as revealed in the following excerpt: "So we're looking at yeah, business capabilities and assessing them for maturity. People, process, technology and information sort of lens" (Retail3). Therefore, the terminology of this benefit is adjusted from only about the improvement of portfolio management to the improvement of portfolio management as well as mapping and optimization capabilities.

Another notable benefit is related to EA's ability in supporting cost management (B6). Many previous studies and EA experts acknowledged this benefit. It is confirmed that EA improves asset management (B4), resource management (B7), and staff management (B9). EA also supports problem scoping (B12) and standards/ regulations compliance (B5).

\section{Strategic benefits}

All of the listed strategic benefits identified in the literature are supported by our empirical data. There are four of those benefits which are supported by all EA experts. Furthermore, there is a new benefit identified in this category. 
Table 2. Identified EA Benefits from Literature Review \& EA Experts Perspectives

\section{ID} Identified Benefits

\begin{tabular}{|c|l|c|}
\hline B2 & Increased efficiency and effectiveness & 8 \\
\hline B3 & Shortened delivery and cycle times & 8 \\
\hline B1 & Improved business operations, processes, and performance & 6 \\
\hline \multicolumn{2}{|c|}{ Managerial } & 9
\end{tabular}

\begin{tabular}{l|l|l|}
8 & 5 & - \\
\hline 8 & 2 & - \\
\hline 6 & 2 & - \\
\hline
\end{tabular}

\begin{tabular}{|c|l|}
\hline B10 & Reduced complexity \\
\hline B8 & Improved risk and change management \\
\hline B11 & Improved portfolio management, mapping capability and optimization capability \\
\hline B6 & Improved cost management \\
\hline B7 & Improved resource allocation and management \\
\hline B12 & Supported scoping \\
\hline B9 & Improved staff/skill management and knowledge \\
\hline B4 & Improved asset lifecycle and management \\
\hline B5 & Improved compliance with regulations/ standards and auditability \\
\hline
\end{tabular}

\begin{tabular}{|l|l|l|}
\hline 9 & 5 & - \\
\hline 7 & 5 & - \\
\hline 2 & 5 & A \\
\hline 9 & 4 & - \\
\hline 5 & 3 & S \\
\hline 2 & 3 & - \\
\hline 3 & 2 & - \\
\hline 2 & 2 & S \\
\hline 2 & 2 & A \\
\hline
\end{tabular}

\begin{tabular}{|l|l|}
\hline \multicolumn{2}{|l}{ Strategic } \\
\hline B23 & Increased quality \\
\hline B20 & Improved project success and organization goal achievement \\
\hline B24 & Provided a roadmap and guidance \\
\hline B25 & Provided strategic recommendation, prioritization and options \\
\hline B15 & Improved business-IT alignment and relationships \\
\hline B14 & Improved alignment to organization strategy and requirement \\
\hline B18 & Improved innovation and new opportunities \\
\hline B22 & Improved strategic decision-making and problem-solving \\
\hline B19 & Improved long-term investments \\
\hline B13 & Improved alignment and relationship with partners \\
\hline B21 & Improved return on investment, profitability and market value \\
\hline B16 & Improved customer orientation/ intelligence \\
\hline B17 & Improved employee and management satisfaction \\
\hline
\end{tabular}

\begin{tabular}{|c|c|c|}
\hline 6 & 5 & - \\
\hline 5 & 5 & $\mathrm{~A}$ \\
\hline 2 & 5 & - \\
\hline- & 5 & $N$ \\
\hline 11 & 4 & - \\
\hline 6 & 4 & - \\
\hline 5 & 4 & - \\
\hline 5 & 4 & - \\
\hline 3 & 4 & - \\
\hline 5 & 3 & - \\
\hline 4 & 3 & - \\
\hline 3 & 3 & - \\
\hline 2 & 2 & - \\
\hline
\end{tabular}

\begin{tabular}{|c|c|c|c|c|}
\hline \multicolumn{5}{|c|}{ IT Infrastructure } \\
\hline B28 & Increased interoperability and integration & 11 & 5 & - \\
\hline B29 & Increased reusability & 3 & 5 & - \\
\hline B31 & Increased standardization & 10 & 4 & - \\
\hline B33 & Reduced waste and redundancy & 6 & 4 & - \\
\hline B32 & Reduced IT costs & 5 & 4 & - \\
\hline B27 & Improved utilization and benefits realization of IT & 4 & 4 & - \\
\hline B34 & Supported deployment, initialization and development of IS & 5 & 3 & - \\
\hline B30 & Increased stability, security, and reliability & 3 & 3 & - \\
\hline $\mathrm{B} 26$ & Improved agility, flexibility, and responsiveness & 12 & 2 & - \\
\hline \multicolumn{5}{|c|}{ Organizational } \\
\hline B35 & Creation and maintenance of common visions & 4 & 4 & - \\
\hline B39 & Provided a holistic view of the organization & 3 & 4 & - \\
\hline B38 & Improved information quality, sharing, and documentation & 7 & 3 & - \\
\hline$B 40$ & Supported positive cultural change & - & 3 & $N$ \\
\hline B36 & Improved communication & 5 & 2 & - \\
\hline B37 & Improved consolidation, synergies, collaboration and reduced conflict of interest & 4 & 2 & - \\
\hline
\end{tabular}

First, in the literature review, it was clearly stated by Kaisler et al. [12] that EA delivers high-quality solutions or projects in organizations (B23). This claim is supported by all EA experts. An EA expert 
affirms that the quality improvement is the most perceived benefit of EA implementation: "A sense of what you believe is quality." (Finance1)

Second, all experts agree that EA increases the possibility of project success and the achievement of organizational goals (B20) which are consistent with Foorthuis [19]. An EA expert asserts: "I think some of the project delivery outcomes have been improved." (Retail1)

Third, Boh and Yellin [20] argue that EA produces a roadmap as a guidance to introduce standardization and integration of organization's infrastructures. All experts provide support for this benefit (B24). For example, an EA expert states that EA gives information on how to achieve the intended future: "It's for having the roadmaps of how we're going to get from where we are." (Retail3)

Fourth, all experts agree that EA supports prioritization by providing a better recommendation and options (B25). For an example, an EA expert affirms: "It has to be sort of done as part of the service of providing informal and formal recommendations on the strategy." (Finance1) This benefit has not been identified earlier in the selected literature. Moreover, another notable benefit which is supported by almost all experts is the ability of EA in improving alignment between business and IT (B15).

It is also confirmed that EA enhances alignment between stakeholders (B13) and overall strategies (B14) and that EA has the ability to support decisionmaking (B22), a long-term investment such as acquisition (B19) and opens new opportunities (B18). Besides, EA increases return on investment (B21), satisfaction (B17) and customer orientation (B16).

\section{IT infrastructure benefits}

All of the listed IT infrastructures are acknowledged by at least 2 EA experts. Furthermore, there are two benefits which are confirmed by all experts involved in this study.

First, Boh and Yellin [20] assert that EA increases the interoperability / integration of IT infrastructures (B28). All experts agree with this claim. An expert commends: "I can see my application, but I can also see the applications that can provide a function so I can see where I can consolidate or reduce my application landscape." (Retail2)

Second, all EA experts agree that EA improves the reusability of infrastructures (B29). "[...] number of different applications, so if I can reuse applications and show how particular applications can be reused, then I get benefit." (Retail3) This is in line with Boucharas et al. [7] who assert that EA supports reusability of infrastructures, IT components and also other technical aspects.
Our study has also confirmed the validity of other benefits identified in the literature including EA decreases the chance of redundancy (B33), improves standardization of infrastructures (B31), reduces cost (32), and enhances flexibility (B26). EA helps the organization in realizing IT benefits (B34), facilitates new systems development and support security, stability and reliability of IT infrastructure (B30).

\section{Organizational benefits}

All listed organizational benefits in literature review were also supported by EA experts. It was confirmed that EA has the ability to create and maintain organization's common vision (B35). EA also provides a holistic view of the organizations (B39). Besides, our study confirms that EA enhances information quality and sharing (B38), including improving the communication in organizations (B36) which leads to stakeholders' collaboration (B37).

There is one new organizational benefit identified based on the interviews. More than half of the experts believe that EA changes people's mindset in the organization from self-orientation to organizationorientation (B40). This benefit has not been identified in the previous studies. An expert said that: "It balanced the IT budget but also took to cover these people's mindset of doing silo project." (Utility1)

\subsection{EA Success Factors}

Thirty-seven success factors have been described by the experts as indicated in Table 3. Seven of those factors have not been previously identified, and nine existing factors have been adjusted. One factor (Framework availability) does not have empirical support. Those thirty-seven success factors comprise nine product quality factors, twelve infrastructure quality factors, seven service delivery quality factors, and nine organizational anchoring factors. The as-is architecture quality, defined EA goals availability, communication and understanding among EA stakeholders are the highest ranked factors for EA success.

\section{Product quality}

Based on the analysis of the interview data, all of the listed product quality success factors identified from the literature review are supported by the interview data. Furthermore, there are two new factors in this category and two factors which are acknowledged by all of the EA experts involved in this study as shown in Table 3 .

First, all experts argue that the quality of EA products is tightly related to the quality of as-is architecture or the depiction of the current state of organizations since EA is a combination of current and future state (F1). An expert said that: "It's a 
combination of both. So some of them are pure as is, and some of them are a bit [futurist]." (Retail1) This is in line with Lange et al. [11] who assert that organizations should provide a complete and holistic view of as-is architecture as part of their EA.

Table 3. Identified EA Success Factors from Literature Review \& EA Experts Perspectives

\section{ID $\quad$ Identified Success Factors $\begin{array}{llll}\mathbf{L}^{1} & \mathbf{E}^{2} & \mathbf{C}^{3}\end{array}$}

\begin{tabular}{|c|l|c|c|c|}
\hline \multicolumn{5}{|c|}{ Product Quality } \\
\hline F1 & As-is architecture quality & 5 & 5 & A \\
\hline F5 & Organization focus oriented & 5 & 5 & - \\
\hline F3 & Roadmap quality & 7 & 4 & A \\
\hline F7 & Iterative refinement & 7 & 4 & - \\
\hline F2 & To-be architecture quality & 4 & 4 & A \\
\hline F6 & Understandable EA & 2 & 4 & - \\
\hline F8 & $\begin{array}{l}\text { Information quality \& } \\
\text { availability }\end{array}$ & - & 4 & $N$ \\
\hline F4 & Principles availability & 7 & 3 & A \\
\hline F9 & Understanding of gaps & - & 1 & $N$ \\
\hline
\end{tabular}

\section{Infrastructure Quality}

\begin{tabular}{|c|l|c|c|c|}
\hline F18 & Defined EA goals & 8 & 5 & - \\
\hline F16 & $\begin{array}{l}\text { Governance formalization } \\
\text { \& availability }\end{array}$ & 7 & 5 & - \\
\hline F12 & $\begin{array}{l}\text { Skills availability \& } \\
\text { allocation }\end{array}$ & 6 & 5 & A \\
\hline F15 & $\begin{array}{l}\text { Decision-making } \\
\text { centralization }\end{array}$ & 6 & 5 & - \\
\hline F17 & Principle establishment & 5 & 5 & - \\
\hline F20 & Accountability & 4 & 5 & - \\
\hline F13 & $\begin{array}{l}\text { Resources availability \& } \\
\text { allocation }\end{array}$ & 8 & 4 & A \\
\hline F10 & Tool support availability & 7 & 4 & - \\
\hline F11 & $\begin{array}{l}\text { Reference architecture } \\
\text { availability }\end{array}$ & 6 & 4 & - \\
\hline F14 & Mandate clarity & 7 & 3 & A \\
\hline F19 & Changes capability & 1 & 1 & - \\
\hline F37 & Framework availability & 6 & - & R \\
\hline \multicolumn{5}{|c|}{ Service Delivery Quality } \\
\hline F21 & Communication quality & 9 & 5 & A \\
\hline F23 & Project support & 6 & 5 & - \\
\hline F24 & Right implementation step & 3 & 5 & A \\
\hline F22 & Management support & 9 & 4 & - \\
\hline F25 & Performance measurement & 5 & 4 & - \\
\hline F26 & $\begin{array}{l}\text { Coaching, facilitating \& } \\
\text { guiding quality }\end{array}$ & - & 4 & $N$ \\
\hline F27 & Consistency & - & 3 & $N$ \\
\hline & \multicolumn{5}{|l|}{ Organizational Anchoring } \\
\hline F30 & $\begin{array}{l}\text { Stakeholders } \\
\text { understanding }\end{array}$ & 9 & 5 & - \\
\hline F32 & EA team involvement & 4 & 5 & - \\
\hline F28 & Top management & 10 & 4 & - \\
\hline
\end{tabular}

\begin{tabular}{|c|l|c|c|c|}
\hline & commitment & & & \\
\hline F29 & Awareness & 5 & 4 & - \\
\hline F31 & Cultural fit & 3 & 4 & - \\
\hline F33 & $\begin{array}{l}\text { Organization-wide } \\
\text { collaboration }\end{array}$ & 4 & 3 & - \\
\hline F34 & Benefit acknowledgement & - & 3 & $N$ \\
\hline F35 & Trust quality & - & 2 & $N$ \\
\hline F36 & Open-minded people & - & 2 & $N$ \\
\hline
\end{tabular}

Note: ${ }^{1}$ Literature Evidence $(\mathrm{n}=15) ;{ }^{2}$ Empirical Evidence ( $\mathrm{n}=5) ;{ }^{3}$ Changes: adjusted (A)/ split (S)/ new $(\mathrm{N})$

Second, in the literature review, it is clearly stated that EA should have a good linkage towards organization strategic goals (F5) [19]. This factor is also agreed by all of the EA experts. Enterprise Architects are expected to guide other stakeholders towards strategic goals through the use EA: "We were smart enough solution architects that we would kind of think enterprise anyway. So we would think a little bit more strategically." (Retail3)

Moreover, EA experts agreed that EA should contain a proper roadmap (F3) including its principles (F4). Furthermore, information embodied in EA should be understandable for all stakeholders (F6) especially the stakeholders who directly interact with EA. It is also confirmed that organizations should refine EA periodically (F7).

Almost all experts also acknowledge the importance of information quality (F8) captured in EA. A new factor related to the importance of gap understanding (F9) has been identified. This is demonstrated by some experts' reference to defining organizations' current and future state, and the gaps between those two: "We do the current state and do the future state, tell us the gaps and all of those things, that part of the thing." (Utility1)

\section{Infrastructure quality}

Almost all of the listed infrastructure factors in our literature review (except Framework availability) are supported by EA experts. Six factors are acknowledged by all of the experts.

First, Kaisler et al. [12] argue that each organization should have a clear and specific reason and goal in implementing EA. Consistently, all experts agree that EA goals need to address organizations' unique requirements (F18): "I think the thing about enterprise architecture services is what you need, there's some basic stuff, but what you need to do in every organization is organization specific." (Retail1)

Second, governance formalization should be available in organizations (F16). Lange et al. [14] explained that a formal governing mechanism is required to support the foundation of EA. An expert 
mention several bodies in his organization which have a role related to EA governance: "We have a forum called the PARG, which is the Project and Architecture Review Group. And that's a monthly meeting, which is; pretty well it's the IT leadership team, plus a few others." (Retail3)

Third, organizations should have a decisionmaking scheme (F15). There should be a group within IT which makes a decision regarding any IT case: "So we have a group within IT who says no." (Retail2) Lange et al. [11] argue that centralization of decision making is required to optimize and increase the achievement of EA goals.

Fourth, EA principles have to be well established across the organizations (F17). This factor is important since the availability of EA principle will not make sense if it is not used and respected by organizations [14]. An expert argues: "If you do $x$ you've deviated from some of the principles and strategies you've got and it's recorded as such in the architecture and is signed off as such." (Finance1)

Fifth, required skills for EA have to be available and allocated to the appropriate part of organizations (F12). Each EA case should be handled by the right people: "So getting it to the right people" (Retail2). Graves [21] added that the skills have to be updated based on each EA maturity level.

Sixth, there should be a clear accountability (F20). Venkatesh et al. [22] argue that local and central accountabilities should be defined to optimize global/ long-term objectives. An expert asserts that it is important to involve business people in deciding solutions: "The division has to make a decision which project they want to take out." (Utility1)

Furthermore, it is confirmed that mandates about EA should be clearly defined (F7). Resources should be available and well allocated (F13). Organizations have to provide tools which are required (F10) and a reference to EA which depicts how each entity relates to others (F11). Moreover, organizations should have a proper change capability (F19).

\section{Service delivery quality}

All factors which have been identified from the literature review are confirmed by the empirical data in our study. Three factors are supported by all of the experts. Also, there are two new factors identified.

First, all experts agree that EA success highly depends on the quality of communications (F21). Two-way communication between business and EA teams is required: "Yes, yeah so where I've been able to talk to people from the business and get their input on the functional model, that's been great." (Retail1) It is in line with Tamm [5] who argues that feedback from stakeholders can be obtained effectively and efficiently if good communication is in place.
Second, all ongoing or future projects have to support EA (F23). Foorthuis [19] explains that the compliance of projects towards EA impacts on the probability of EA success. All experts acknowledge the relevance of this factor. An expert mentions a way to keep projects in line with the EA is by providing the right architect: "I put the right architect on every project to actually ensure those projects are helping us move along that path." (Retail3)

Third, Kaisler et al. [12] argue that EA should be implemented gradually. However, the findings of the interviews suggest a slightly different perspective. An EA expert asserts that the most important aspect is not about gradual implementation, but about the most appropriate approach for each organization: “...you are not necessary able to do it by incrementally building on the widgets that you've got. Sometimes you need a quantum leap." (Finance1) Therefore, this factor's terminology is adjusted from "gradual implementation" to "right implementation steps".

Moreover, EA experts in our study confirmed the following factors. Management should support EA since limited support from management is a threat for the EA (F22). Also, the performance of EA should be measured to track its benefits and to be used as an input of EA refinement (F25).

Furthermore, almost all of experts agree on the importance of the availability of a role that guides, facilitates and coach stakeholders towards EA (F26), as indicated in the following interview excerpt: "So what we did was we picked up their business capabilities and asked them to assess it rather than us assessing it." (Utility1) Also, three experts assert that both EA team and stakeholders should be consistent and in line with the direction of EA (F27).

\section{Organizational anchoring}

Three new success factors in this category have been identified. Furthermore, there are two factors that are acknowledged by all of the EA experts.

First, stakeholders should have a proper understanding towards EA (F30). All experts agree with this factor. As explained by an expert that misunderstanding of EA can become a hindrance of EA success: "So I think some of them have not understood what enterprise architecture is, what the value of it is and how to manage that value." (Utility1) Both business and IT need to have a common understanding towards EA [11,21].

Second, all experts argue that EA team should be involved in organizations' activities as close as possible (F32). An expert described how the EA team is involved in the organization: "So we get contacted, or we work across projects or business problem areas." (Retail2) This is in line with Foorthuis [19] who asserts that EA team should actively participate. 
Our empirical study has identified three new factors. First, the importance of acknowledging EA benefits (F34) is recognized. Not all stakeholders are able to perceive the benefits of EA. Stakeholders should trust that EA is good for them (F35). An expert said that trust with the EA team makes EA implementation easier: "So that's how I've found is the easiest way so now I've got that trust relationship there. It's far simpler." (Finance1). Also, stakeholders should be open-minded towards EA (F36) otherwise they will become a hindrance for EA success: "So that was one of the biggest barriers you can say is people mindset and other thing." (Utility1)

Finally, in order to anchor EA in organizations, top management commitment should be available and maintained (F28). Awareness of all stakeholders towards EA (F29) and collaboration between them (F33) are also required. Furthermore, EA should consider the cultural aspects of organizations and fit the organizations' culture (F31).

\subsection{Summary of the Key Findings}

We summarize the study findings by proposing a simple model called Enterprise Architecture Success Factor and Benefit Model (EA-SFBM). This model highlights the different types of EA benefits and EA success factors. As shown in Figure 1, the model contains two main elements. The left element describes four categories of factors which affect EA success: product quality factors, infrastructure quality factors, service delivery quality factors, and organizational quality factors. The right element describes five categories of EA benefits: operational benefits, managerial benefits, strategic benefits, IT infrastructure benefits, and organizational benefits.

As described in Tables 2 and 3, almost all of EA benefits and success factors from the literature review are well supported by EA experts in this study. Nearly $25 \%$ of the listed EA benefits from the literature review are agreed by all of the participated EA experts. Almost $45 \%$ of the identified EA success factors from the existing literature are acknowledged too. Furthermore, those two tables expose that most of the benefits or success factors which are mentioned in the majority of the selected studies are also clarified by most of the EA experts. For example, the EA benefits to increase interoperability and integrations (B28) among IT infrastructure group is mentioned by eleven of fifteen selected studies and agreed by five of five EA experts in this study. Thus, this study has enhanced the understanding in this area by offering some empirical evidence and explanation of EA benefits and success factors.

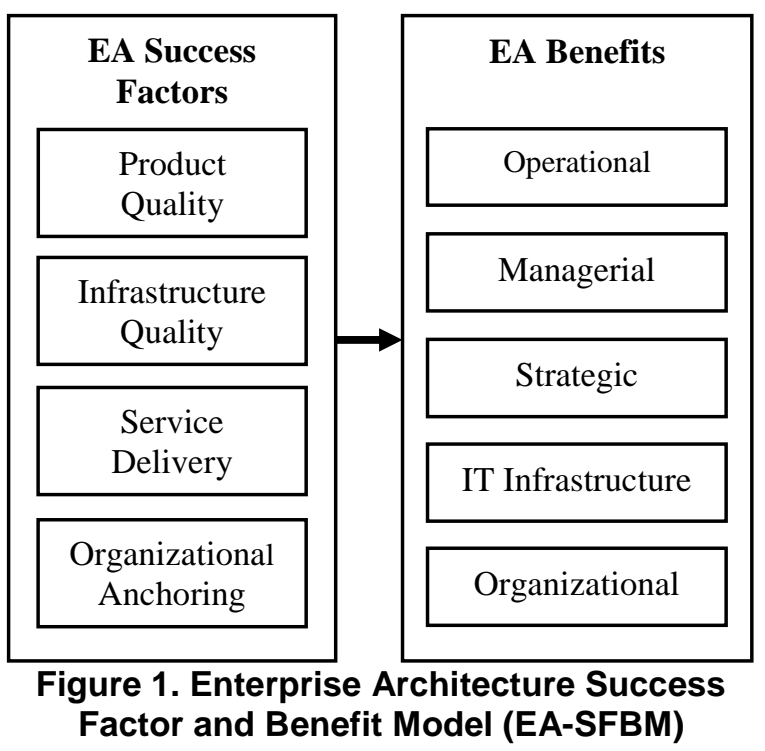

Moreover, the model shows that in achieving the identified five categories of EA benefits, organizations should consider those four categories of EA success factors. This model can be used to guide future research in investigating EA benefits and benefit drivers to complement the findings of our study. The model also helps practitioners to be aware of what benefits can be expected from EA investments and what factors need to be managed to increase the likelihood of achieving the benefits.

\section{Conclusion}

In this study, we have identified a list of EA benefits and success factors based on a critical literature analysis and synthesis, which have been preliminarily validated through interviews with five Enterprise Architects from five Australian organizations. The qualitative interviews also helped identify additional EA benefits and success factors which have not been identified in the previous studies. In particular, this study has identified forty EA benefits that can be grouped into five categories: operational benefits, managerial benefits, strategic benefits, IT infrastructure benefits, and organizational benefits. Furthermore, thirty-seven EA success factors have been identified and categorized into four groups: product quality factors, infrastructure quality factors, service delivery quality factors, and organizational quality factors. Almost all of the listed EA benefits and EA success factors in the existing literature have been confirmed by the EA experts involved in our study. Moreover, there are a number of new benefits and success factors which have not been discussed in the previous studies. 
This study contributes to research and practice. In terms of research, this study has offered a preliminary validation of previous knowledge claims about EA benefits and success factors. This study reduces any uncertainties about the benefits of EA and ambiguity of EA success factors. In terms of practical contributions, the validated EA benefits help organizations manage their expectation towards EA. Moreover, the listed success factors can be used as a guide by organizations in gaining EA benefits. Besides, this study has introduced EA Success Factor and Benefit Model (EA-SFBM) as a summary of the overall findings. This model can be used as a guidance for future work in this area.

The findings of this study could be further improved by incorporating additional interviews with EA experts that have been conducted as part of a larger research project. In addition, exploring the experience of other types of organizations within and beyond Australia, including governmental or public service institutions could complement the study findings. Furthermore, the relationship between elements of the EA-SFBM could be further explored in future studies to enrich the understanding of how EA delivers value to organizations.

\section{References}

[1] Zachman, J.A., The Expert Opinion. Journal of Information Technology Cases \& Applications, 2002. 4(3): p. 7.

[2] Land, M.O.t., et al., Enterprise Architecture: Creating Value by Informed Governance. The Enterprise Engineering Series. 2009, Berlin: Springer.

[3] GAO, Information Technology: Leadership Remains Key to Agencies Making Progress on Enterprise Architecture Efforts. 2003, Government Accountability Office: Washington.

[4] Alwadain, A.S.A., A model of enterprise architecture evolution, in Information Systems School, Faculty of Science and Engineering. 2014, Queensland University of Technology: Queensland.

[5] Tamm, T., The Organisational Benefits and Key Success Factors of Enterprise Architecture, in Departement of Information Systems. 2012, University of Melbourne: Melbourne.

[6] Frampton, K., et al. Enterprise Architecture Service Provision: Pathways to Value. in 23rd European Conference on Information Systems. 2015. Munster, Germany: Association for Information Systems.

[7] Boucharas, V., et al., The Contribution of Enterprise Architecture to the Achievement of Organizational Goals: A Review of the Evidence, in Trends in Enterprise Architecture Research, E. Proper, et al., Editors. 2010, Springer Berlin Heidelberg: Delft, The Netherlands. p. 1-15.
[8] Niemi, E. and S. Pekkola. Adapting the DeLone and McLean Model for the Enterprise Architecture Benefit Realization Process. in 42nd Hawaii International Conference on System Sciences. 2009. Big Island: IEEE.

[9] Cardwell, G., The Influence of Enterprise Architecture and Process Hierarchies on Company Success. Total Quality Management \& Business Excellence, 2008. 19(1/2): p. 47-55.

[10] Foorthuis, R., et al. On Course, but not There Yet: Enterprise Architecture Conformance and Benefits in Systems Development. in International Conference on Information Systems. 2010. St. Louis: AIS.

[11] Lange, M., et al., Realizing Benefits from Enterprise Architecture: a Measurement Model, in 20th European Conference on Information Systems (ECIS). 2012, Association for Information Systems: Barcelona, Spain.

[12] Kaisler, S.H., et al., Enterprise Architecting: Critical Problems. in 38th Annual Hawaii International Conference on System Sciences. 2005. Hawaii: IEEE.

[13] Niemi, E. Enterprise Architecture Benefits: Perceptions from Literature and Practice. in 7th IBIMA Conference Internet \& Information Systems in the Digital Age. 2008. Brescia, Italy: University of Jyväskylä, Information Technology Research Institute.

[14] Lange, M., et al., An Empirical Analysis of the Factors and Measures of Enterprise Architecture Management Success. European Journal of Information Systems, 2015: p. 1-21.

[15] Gregor, S., et al., Enterprise architectures: Enablers of Business Strategy and IS/IT Alignment in Government. Information Technology \& People, 2007. 20(2): p. 25.

[16] Atieno, O.P., An analysis of the strengths and limitation of qualitative and quantitative research paradigms. Problems of Education in the $21 \mathrm{st}$ Century, 2009. 13(1): p. 13-38.

[17] Merriam, S.B., Qualitative Research: A Guide to Design and Implementation. 2014, Hoboken: Wiley. 322.

[18] Shang, S. and P.B. Seddon, Assessing and Managing the Benefits of Enterprise Systems: the Business Manager's Perspective. Information Systems Journal, 2002. 12(4): p. 271-299.

[19] Foorthuis, R., Project Compliance with Enterprise Architecture, in Department of Information and Computing Sciences, Organization and Information. 2012, Utrecht University: Utrecht, The Netherlands.

[20] Boh, W.F. and D. Yellin, Using Enterprise Architecture Standards in Managing Information Technology. Journal of Management Information Systems, 2006. 23(3): p. 163-207.

[21] Graves, T., Enterprise Architecture: a Pocket Guide. 2009, IT Governance Pub., 2009.: Ely, United Kingdom.

[22] Venkatesh, V., et al., Enterprise Architecture Maturity: the Story of The Veterans Health Administration. MIS Quarterly Executive, 2007. 6(2): p. 79-90. 